\title{
Método eficiente, baseado em leitores de microplaca, para detecção de resistência a fungicidas triazóis (IDM) e estrobirulinas (IQe) em populações do patógeno da brusone do trigo
}

\author{
Priscila Santos Casado ${ }^{1,2}$, Giselle de Carvalho ${ }^{1,3}$, Paulo Cezar Ceresini ${ }^{1}$, Vanina Lilian Castroagudín ${ }^{1,4}$, Omar Jorge \\ Sabbag ${ }^{1,5}$, Samara Nunes Campos Vicentini ${ }^{1,6}$, João Leodato Nunes Maciel ${ }^{7}$
}

Universidade Estadual Paulista - UNESP, Campus de Ilha Solteira, CEP 15385-000, Ilha Solteira, SP, Brasil. Tel. +55 (18) 3743-1948. ${ }^{2}$ pscasado0@

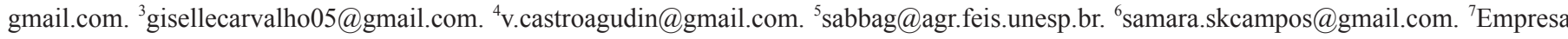
Brasileira de Pesquisa Agropecuária - EMBRAPA Trigo, Passo Fundo, RS, Brasil. Tel. +55 (54) 3316-5800. joao.nunes-maciel@embrapa.br . Autor para correspondência: Paulo Cezar Ceresini (paulo.ceresini@bio.feis.unesp.br)

Data de chegada: 11/09/2017. Aceito para publicação em: 04/11/2017.

$10.1590 / 0100-5405 / 185072$

\section{RESUMO}

Casado, P. S.; Carvalho, G.; Ceresini, P.C.; Castroagudín, V.L.; Sabbag, O.J.; Vicentini, S.N.C.; Maciel, J.L.N. Método eficiente, baseado em leitores de microplaca, para detecção de resistência a fungicidas triazóis (IDM) e estrobirulinas (IQe) em populações do patógeno da brusone do trigo. Summa Phytopathologica, v.44, n.3, p.236-244, 2018.

Esta pesquisa propõe a utilização de um método baseado em leitor automatizado de microplacas para detectar resistência a fungicidas triazóis (IDM) e estrobirulinas (IQe) em populações do fungo hemibiotrófico fitopatogênico Pyricularia graminis-tritici (Pygt) do trigo. A disponibilidade de método acurado, mais rápido e eficiente para a detecção da redução da sensibilidade a fungicidas contribuiria para facilitar a tomada de decisão sobre o manejo químico da brusone do trigo no país. Há informação sobre redução da sensibilidade de triazóis no controle da brusone do trigo e evidências da ocorrência generalizada de redução da sensibilidade à estrobilurinas em populações do patógeno no Brasil. O método de microplaca foi acurado em discriminar a variação fenotípica na sensibilidade entre isolados do patógeno aos fungicidas IDM tebuconazol e epoxiconazol e ao fungicida IQe azoxistrobina. Economicamente, ambos os métodos representam alto custo, portanto, é necessário comparar a eficiência desses métodos. O método de microplacas foi mais eficiente no uso de recursos, com custo operacional total $33 \%$ inferior ao do método de placas de Petri. Em conjunto, os fatores acurácia, rapidez e eficiência no uso de recursos indicaram que o método de microplaca pode ser utilizado no monitoramento da resistência a fungicidas em populações do fungo da brusone do trigo no agroecossistema brasileiro.

Palavras-chave: $\mathrm{EC}_{50}$ acurácia; rapidez; recursos; eficiência; custos.

\section{ABSTRACT}

Casado, P. S.; Carvalho, G.; Ceresini, P.C.; Castroagudín, V.L.; Sabbag, O.J.; Vicentini, S.N.C.; Maciel, J.L.N.Efficient method, based on microplate readers, to detect resistance to triazole (DMI) and strobilurin (QoI) fungicides in wheat blast pathogen populations. Summa Phytopathologica, v.44, n.3, p.236-244, 2018

This study proposes the application of a method based on an automated microplate reader to detect resistance to triazole (DMI) and strobilurin (QoI) fungicides in populations of the plant pathogenic hemibiotrophic fungus Pyricularia graminis-tritici (Pygt) from wheat. Availability of an accurate, more rapid and efficient method to detect eventual reduction in sensitivity to fungicides could contribute to facilitate the decision making on chemical management of wheat blast in the country. There are reports of reduction in the sensitivity of triazoles to control wheat blast and evidence of widespread reduction in the sensitivity to strobilurins in populations of the pathogen in Brazil. The microplate method was accurate in discriminating the phenotypic variation in sensitivity among isolates of the pathogen to the DMI fungicides tebuconazole and epoxiconazole and to the QoI fungicide azoxystrobin. Economically, both methods represent high cost, therefore, the efficiency of these methods should be compared. The microplate method was more efficient in the use of resources, with a total operating cost $33 \%$ inferior to that of the Petri dish method. Together, the factors accuracy, celerity and efficiency in the use of resources indicated that the microplate method can be used to monitor resistance to fungicides among populations of the wheat blast fungus in the Brazilian agroecosystem.

Keywords: EC $\mathrm{E}_{50}$; accuracy; celerity; resources; efficiency; costs.

Desde os anos 70, o número de casos de fungos fitopatogênicos resistentes a fungicidas vem aumentando consideravelmente na agricultura, tornando-se um fator limitante a prejudicar o manejo químico de doenças, uma vez que os fungicidas tornam-se ineficazes (11). Surpreendentemente, no Brasil as contribuições da pesquisa que quantificam a magnitude do impacto da resistência de fungicidas nos mais diversos patossistemas locais têm sido escassas, limitando-se a revisões de literatura ou a estudos pontuais $(5 ; 9 ; 12 ; 13 ; 23)$. Talvez por essa escassez de informação sobre o cenário atual da resistência a fungicidas na agricultura brasileira, não há relatos de qualquer iniciativa para implementação de um sistema local de monitoramento como estratégia para manejar a emergência da resistência e os impactos pós-emergência associados com a redução da eficácia dos fungicidas em culturas de importância agrícola (28).

Mesmo mundialmente, são escassos os exemplos de sistemas de monitoramento da resistência a fungicidas em populações 
de fitopatógenos na agricultura que possibilitem aos produtores de determinada cultura a tomada de decisão, em tempo real, em substituir fungicidas na eventualidade da constatação de resistência a princípios ativos de alto risco. Como exceção à regra, no Reino Unido pesquisadores desenvolveram e implementaram o único sistema de detecção e monitoramento, em tempo real, da redução da sensibilidade a fungicidas em populações de fitopatógenos do trigo (18).

A viabilização da implementação de um sistema semelhante de monitoramento da resistência a fungicidas em fungos fitopatogênicos no país depende do desenvolvimento de métodos acurados, rápidos e eficientes de detecção (15). Há vários métodos convencionais utilizados para detecção e monitoramento da variação fenotípica na sensibilidade de fungos necrotróficos e hemi-biotróficos a fungicidas, visando evidenciar a ocorrência de redução da sensibilidade em populações de fitopatógenos. Esses métodos convencionais são baseados na análise relativa do crescimento micelial in vitro em meios de cultura suplementados com doses discriminatórias de fungicidas ou com doses seriadas para determinar a $\mathrm{EC}_{50}$ (concentração efetiva do fungicida capaz de inibir $50 \%$ do crescimento micelial) populacional $(6 ; 7 ; 16)$. Entretanto, os métodos convencionais são, em sua maioria, muito demorados, pouco acurados devido à dependência de critérios visuais e manuais nas avaliações, e ineficientes no uso de recursos requerendo centenas a milhares de placas de Petri de meio de cultura (2). Além disso, esses métodos convencionais são potencialmente mais prejudiciais ao meio ambiente em função da geração de maior quantidade de material de descarte com resíduos tóxicos de fungicidas $(1 ; 27)$.

Para acelerar o processo de detecção da redução da sensibilidade a fungicidas em populações de fitopatógenos propôs-se o uso do método de microplacas otimizado para esta finalidade específica (14). O método de microplacas é baseado na medida simples da biomassa fúngica ou da atividade cinético-microbiana em reposta ao efeito de diferentes doses de fungicidas $(3 ; 4 ; 17 ; 19)$. O fungo é cultivado em meio de cultura líquido em um poço da microplaca e o crescimento ou a atividade cinética microbiana são medidos por meio da absorbância de luz que resulta da variação da turbidez ou da intensidade de fluorescência em decorrência do ataque enzimático a um substrato específico $(3 ; 4 ; 17$; 30). Como a avaliação da inibição do crescimento micelial na presença de fungicidas se baseia no uso de tecnologia de leitura automatizada da absorbância de luz em dezenas de amostras simultaneamente, esse método é potencialmente mais rápido, mais acurado e mais eficiente. Isso porque leitores de microplacas possuem sistemas operacionais que reduzem o tempo envolvido no tratamento de dados, uma vez que se baseiam em leitura de valores de absorbância e cálculos da resposta fenotípica de maneira automática $(3 ; 17)$.

Como referencial para implementar o método de microplacas para detecção de resistência a fungicidas em um patossistema fúngico particular recomenda-se que: i) o volume total de suspensão dentro de cada poço da microplaca deve estar entre 75 e $200 \mu \mathrm{L}$, ii) a concentração inicial da suspensão de esporos deve estar no mínimo a $10^{4}$ esporos $\mathrm{mL}^{-1}$ e iii) o comprimento de onda utilizado para a leitura da absorbância deve ser especificamente selecionado para cada fungo fitopatogênico e sistema específico de deteç̧ão $(15 ; 18)$.

Se a otimização do método de microplacas para detecção e monitoramento da redução da sensibilidade a fungicidas em populações do fungo da brusone do trigo for bem-sucedida, poderá ser utilizada para nortear a tomada de decisão, em tempo real (i.e., durante a própria safra), sobre o manejo químico dessa doença foliar, mas principalmente de espigas.

No presente estudo, propôs-se o desenvolvimento do método de microplaca para a medida do crescimento fúngico como mais rápido, acurado e eficiente para discriminar e quantificar a sensibilidade das populações do fungo fitopatogênico Pyricularia graminis-tritici (Pygt), agente causal da brusone do trigo no Brasil, aos fungicidas triazóis [ou inibidores da desmetilação de esteróis (IDM)] tebuconazol e epoxiconazol e à estrobirulina [ou inibidores da quinona externa (IQe)] azoxistrobina. A brusone é considerada a principal doença do trigo no Brasil, e há indícios da ineficácia de triazóis $(10 ; 25)$ e evidências da ocorrência generalizada de resistência a estrobilurinas em populações do patógeno no Brasil $(5 ; 24)$.

Para atingir esse objetivo específico, foram efetuadas: i) análise da acurácia do método em discriminar os fenótipos de resistência e sensibilidade de populações de Pygt da brusone do trigo aos fungicidas IDM e IQe com base na $\mathrm{EC}_{50}$; ii) análise do rendimento relativo do método de microplacas em relação ao método de placas de Petri, considerando o número efetivo de amostras analisadas num tempo fixo (como medida de rapidez); e iii) análise econômica comparativa entre os métodos de microplaca e de placa de Petri, usando estimativas do custo operacional total como medida de eficiência no uso de recursos.

\section{MATERIAL E MÉTODOS}

Os isolados do patógeno utilizados nesse estudo foram obtidos de amostras populacionais de $P$. graminis-tritici da brusone do trigo e de P. oryzae (Po) do arroz provenientes de Mato Grosso do Sul (MS) e Goiás (GO) no centro-sul do Brasil nos anos de 2007, 2012 e 2013, os quais se encontram preservados na micoteca da UNESP Campus de Ilha Solteira (Tabela 1). No total foram utilizados treze isolados de $P y g t$, além de quatro isolados de Po do arroz obtidos do Tocantins (TO). Os isolados de $P o$ foram incluídos no estudo pois representam o único grupo de isolados com padrão de sensibilidade a fungicidas triazóis IDM disponíveis (25). Todos esses isolados representam diferentes genótipos multiloci microssatélites $(5 ; 21)$ e haplotipos com mutações distintas nos genes cyp51A (cyp51A H1 ou cyp51A H6) ou $c y t B(c y t B$ $\mathrm{H} 1$ ou $c y t B$ H9) que conferem fenótipo de sensibilidade ou resistência aos fungicidas IDM ou IQe, respectivamente $(5 ; 24 ; 25)$.

A acurácia do método de microplacas em discriminar os fenótipos de resistência e sensibilidade in vitro aos fungicidas IDM tebuconazol e epoxiconazol e ao IQe azoxistrobina, foi determinada comparandose o fenótipo obtido para cada isolado analisado com aquele obtido anteriormente no método de placas de Petri (Tabela 1).

Para implementação do método de microplacas, utilizou-se equipamento do tipo leitor de microplaca (Multiskan ${ }^{\mathrm{TM}} \mathrm{FC}$ Microplate Photometer, Thermo Scientific ${ }^{\mathrm{TM}}$, EUA) de forma semelhante ao descrito por Fraaije et al. (14) para medida do crescimento, porém com modificações. Para comparação entre métodos, utilizou-se os dados fenotípicos qualitativos (Tabela 1) e quantitativos obtidos por Oliveira et al. (24) e Poloni et al. (25) que empregaram o método de placas de Petri na fenotipagem da resistência/sensibilidade dos mesmos isolados de Pygt da brusone do trigo aos fungicidas IQe e IDM, respectivamente.

Os isolados de Pygt foram reativados em meio BDA $\left(20,7 \mathrm{~g} \mathrm{~L}^{-1}\right.$ de batata dextrose, $15 \mathrm{~g} \mathrm{~L}^{-1}$ ágar) e os isolados de $P o$ foram reativados em meio de aveia ( $60 \mathrm{~g} \mathrm{~L}^{-1}$ de aveia, $15 \mathrm{~g} \mathrm{~L}^{-1}$ ágar), ambos com adição de cloranfenicol e estreptomicina $\left(50 \mu \mathrm{g} \mathrm{mL}^{-1}\right.$ de cada). Após sete dias da reativação das culturas, transferiu-se discos de micélio para placas contendo meio BDA e incubou-se por quinze dias a $24^{\circ} \mathrm{C}$ e 12 $\mathrm{h}$ de fotoperíodo. Para a coleta dos esporos foi realizada a raspagem superficial do micélio com o auxílio de uma espátula esterilizada na 
Tabela 1. Descrição dos isolados de Pyricularia graminis-tritici e de P. oryzae selecionados para analisar a acurácia do método de microplacas na discriminação dos fenótipos de resistência e sensibilidade a fungicidas triazóis (IDM) e estrobirulinas (IQe)

\begin{tabular}{|c|c|c|c|c|c|c|c|}
\hline \multirow[t]{2}{*}{$\begin{array}{l}\text { Espécie e } \\
\text { isolados }\end{array}$} & \multirow[t]{2}{*}{ Local de origem e safra de coleta } & \multicolumn{3}{|c|}{$\begin{array}{l}\text { Haplotipo do gene cyp51A e fenótipo para } \\
\text { fungicidas triazóis (IDM) } \\
\end{array}$} & \multicolumn{3}{|c|}{$\begin{array}{c}\text { Haplotipo do gene } c y t B \text { e fenótipo para } \\
\text { fungicidas estrobirulinas (IQe) }\end{array}$} \\
\hline & & Haplotipo & NCBI & Fenótipo & Haplotipo & NCBI & Fenótipo \\
\hline \multicolumn{8}{|c|}{ Pyricularia graminis-tritici de trigo } \\
\hline 12.1 .129 & Amambaí e Aral Moreira, MS, 2012/2013 & cyp51A $\mathrm{H} 1$ & KX620438 & Resistente & cytB H9 & KM023783 & Sensível \\
\hline 12.1.132 & & cyp $51 A \mathrm{H} 1$ & KX620438 & Resistente & $c y t B \mathrm{H} 9$ & KM023783 & Sensível \\
\hline 12.1.130 & & cyp51A $\mathrm{H} 1$ & KX620438 & Resistente & $c y t B \mathrm{H} 9$ & KM023783 & Sensível \\
\hline 12.1 .150 & & cyp51A H1 & KX620438 & Resistente & $c y t B \mathrm{H} 9$ & KM023783 & Sensível \\
\hline 12.1.237 & & cyp51A $\mathrm{H} 1$ & KX620438 & Resistente & $c y t B \mathrm{H} 9$ & KM023783 & Sensível \\
\hline 12.1.239 & & cyp51A H1 & KX620438 & Resistente & $c y t B \mathrm{H} 9$ & KM023783 & Sensível \\
\hline 12.1.240 & & cyp51A $\mathrm{H} 1$ & KX620438 & Resistente & $c y t B \mathrm{H} 9$ & KM023783 & Sensível \\
\hline 12.1 .280 & & cyp51A H1 & KX620438 & Resistente & $c y t B \mathrm{H} 9$ & KM023783 & Sensível \\
\hline 12.1 .127 & & cyp51A H1 & KX620438 & Resistente & $\operatorname{cyt} B \mathrm{H} 1$ & KM023775 & Resistente \\
\hline 12.1 .146 & & cyp51A H1 & KX620438 & Resistente & $c y t B \mathrm{H} 1$ & KM023775 & Resistente \\
\hline 12.1 .028 & Rio Verde, GO, 2012/2013 & cyp51A H1 & KX620438 & Resistente & $c y t B \mathrm{H} 1$ & KM023775 & Resistente \\
\hline 12.1 .030 & & cyp51A H1 & KX620438 & Resistente & $c y t B \mathrm{H} 1$ & KM023775 & Resistente \\
\hline 12.1 .068 & & cyp51A H1 & KX620438 & Resistente & $c y t B \mathrm{H} 1$ & KM023775 & Resistente \\
\hline \multicolumn{8}{|c|}{ Pyricularia oryzae ${ }^{\mathrm{c}}$} \\
\hline 630 & TO, 2007 & cyp51A H6 & KX620437 & Sensível & $\mathrm{ND}^{\mathrm{d}}$ & - & ND \\
\hline 364 & & cyp51A H6 & KX620437 & Sensível & & & \\
\hline 704 & & cyp51A H6 & KX620437 & Sensível & & & \\
\hline 656 & & cyp51A H6 & KX620437 & Sensível & & & \\
\hline
\end{tabular}

${ }^{a}$ Caracterizados por Poloni et al. (25); ${ }^{\mathrm{b}}$ Caracterizados por Castroagudín et al. (5) e Oliveira et al. (24). ${ }^{\mathrm{c}}$ Isolados de $P$. oryzae (Po) foram incluídos como controle pois não se detectou sensibilidade a fungicidas triazóis nas populações de isolados de $P$. graminis-tritici. ${ }^{\mathrm{d}} \mathrm{ND}$ Não determinado para este estudo uma vez que se detectou isolados de Pygt sensíveis para azoxistrobina. Entretanto, conhece-se que os isolados carregam o alelo cytb H9 e são sensíveis à azoxistrobina (5).

presença de água destilada esterilizada acrescida do espalhante adesivo Tween $80\left(2\right.$ gotas $\left.\mathrm{L}^{-1}\right)$. A concentração da suspensão de esporos foi determinada em câmara de Neubauer, ajustando-se para $2 \times 10^{4}$ esporos $\mathrm{mL}^{-1}$.

O experimento consistiu na análise de treze isolados de Pygt e quatro isolados de Po. Para o grupo de fungicidas IDM tebuconazol e epoxiconazol, foram utilizados os seguintes tratamentos: 13 isolados de trigo, quatro isolados de arroz, sete a nove doses dos fungicidas (Tabela 2), totalizando 127 parcelas experimentais cada. Para o fungicida IQe azoxistrobina foram utilizados os seguintes tratamentos: 13 isolados de trigo e 12 doses do fungicida (Tabela 2), totalizando 156 parcelas experimentais. $\mathrm{O}$ volume total dispensado em cada poço da placa foi de $130 \mu \mathrm{L}$, distribuídos como segue: controle positivo $(120 \mu \mathrm{L}$ de caldo BD sem adição dos fungicidas $+10 \mu \mathrm{L}$ da suspensão de esporos), branco ou controle negativo $(130 \mu \mathrm{L}$ de caldo $\mathrm{BD}$ com adição das distintas doses de fungicidas) e as demais amostras $(120 \mu \mathrm{L}$ de caldo BD com adição das doses de fungicidas $+10 \mu \mathrm{L}$ da suspensão de esporos).

Para o experimento com fungicidas triazóis, a suspensão de

Tabela 2. Concentrações utilizadas dos fungicidas Folicur EC (tebuconazol a 200g L $\mathrm{g}^{-1}$, Bayer), Tango Cash (epoxiconazol a $75 \mathrm{~g} \mathrm{~L}$, , BASF) e Priori (Azoxistrobina a $250 \mathrm{~g} \mathrm{~L}^{-1}$, Syngenta) para determinação da $\mathrm{EC}_{50}$ de isolados de Pyricularia graminis-tritici do trigo e de P. oryzae do arroz

\begin{tabular}{|c|c|c|c|c|c|c|c|c|c|}
\hline Espécie & Fungicidas & & & Concent & $\tilde{\mathbf{o} e s}(\mu \mathrm{g}$ & & & & Total de doses \\
\hline \multirow{4}{*}{ Pyricularia graminis-tritici } & Tebuconazol & 0,00 & 0,30 & 0,75 & 0,90 & 1,80 & 4,10 & 6,80 & 7 \\
\hline & Epoxiconazol & 0,00 & 0,04 & 0,10 & 0,30 & 0,68 & 1,00 & 2,00 & 7 \\
\hline & \multirow{2}{*}{ Azoxistrobina } & 0,00 & 0,02 & 0,04 & 0,08 & 0,16 & 0,32 & 0,63 & \\
\hline & & 1,25 & 2,50 & 5,00 & 7,00 & 10,00 & - & - & 12 \\
\hline \multirow{4}{*}{ P. oryzae } & \multirow[t]{2}{*}{ Tebuconazol } & 0,0000 & 0,0025 & 0,0050 & 0,0100 & 0,0200 & 0,0400 & 0,0750 & \\
\hline & & 0,1500 & 0,3000 & - & - & - & - & - & 9 \\
\hline & \multirow{2}{*}{ Epoxiconazol } & 0,0000 & 0,0013 & 0,0025 & 0,0050 & 0,0100 & 0,0200 & 0,0375 & \\
\hline & & 0,0750 & 0,1120 & - & - & - & - & - & 9 \\
\hline
\end{tabular}


esporos foi mantida por dezoito horas em câmara de crescimento a $24^{\circ} \mathrm{C}$ e $12 \mathrm{~h}$ de fotoperíodo para a germinação dos esporos. No experimento com o fungicida azoxistrobina IQe, ao caldo BD (20,7 $\mathrm{g} \mathrm{L}^{-1}$ batata-dextrose) foi acrescido $0,5 \mathrm{mM}$ de ácido salicilhidroxâmico (SHAM), fundamental para suprimir a via alternativa da oxidase acompanhando os procedimentos relatados por Ma et al. (20). As concentrações dos fungicidas utilizadas (Tabela 2) foram pré-determinadas em experimento piloto. O crescimento dos isolados foi determinado com base na absorbância de luz à $620 \mathrm{~nm}$ obtida no leitor de microplacas descrito acima, 96 h após o início do experimento. Os valores obtidos foram utilizados para cálculo da $\mathrm{EC}_{50}$ (concentração que inibe $50 \%$ do crescimento do micélio) de cada isolado, e para cada fungicida, por meio do programa $\mathrm{ED}_{50}$ plus v1.0 (29). Os experimentos consistiram de blocos casualizados, com cinco repetições por tratamento. $\mathrm{O}$ experimento foi repetido uma vez. A análise de variância (ANOVA) e o teste de comparação de médias (Scott-Knott) a 5\% de probabilidade, foram efetuados no ambiente R com o uso do pacote estatístico Agricolae (26).

A eficiência relativa no uso de recursos com o método de microplacas e com o de placas de Petri foi determinada e os custos operacionais efetivo (COE) e total (COT) comparados, como proposto por (22). O COE foi composto das despesas com mão de obra e materiais utilizados em laboratório para ambos os métodos. Já o COT foi composto pelo COE, acrescido de outras despesas calculadas, bem como da depreciação estimada pelo método linear, proporcional ao período de utilização mensal do laboratório, em relação ao conjunto de elementos correspondentes ao capital fixo da atividade associados à vida útil de cada bem permanente.

Essa informação é relevante para os laboratórios interessados em implementar e oferecer serviços de detecção de resistência a fungicidas em populações de patógenos no país usando método semelhante de análise. É relevante, também, para os produtores rurais, potenciais usuários finais desse serviço de detecção. Os preços empregados foram em moeda Dólar (US\$), referente ao dia 14 de julho de 2017.

\section{RESULTADOS E DISCUSSÃO}

Provavelmente este é o primeiro estudo em que se propõe o uso do método de microplaca para discriminação entre os fenótipos de resistência e de sensibilidade a fungicidas triazóis e estrobirulinas em populações de Pygt e Po (Figura 1), com o objetivo de nortear a tomada de decisão quanto ao manejo químico da brusone do trigo no Brasil. Sob o ponto de vista qualitativo, o grupo de isolados de $P o$ descritos como sensíveis aos fungicidas IDM triazóis pelo método de placas de Petri (25), também foi caracterizado como sensível quando avaliado pelo método de microplaca.

Analisando-se a curva dose-resposta média, foi possível discriminar o grupo de isolados de Pygt descritos como resistentes a triazóis (25) do grupo dos isolados de $P o$ sensíveis a triazóis, demonstrando a acurácia do método de microplacas (Figura 2).

Estes isolados apresentaram valores de absorbância para a curva dose-resposta decrescendo de 2,007 para 0 em função do incremento de doses do fungicida entre 0 e $0,16 \mu \mathrm{g} \mathrm{mL}^{-1}$ de azoxistrobina. Por sua vez, os cinco isolados de Pygt (12.1.028, 12.1.030, 12.1.068, 12.1.127, 12.1.146) classificados por Oliveira et al. (24) como resistentes no método de placas de Petri foram também resistentes pelo método de microplacas, tendo sido detectados valores de absorbância para a curva dose-resposta decrescendo de 1,120 para o mínimo de 0,20 na dose de $10 \mu \mathrm{g} \mathrm{mL}^{-1}$. Verificou-se que esses isolados resistentes a azoxistrobina apresentam crescimento micelial em todas as doses do produto, o que não ocorreu com os isolados sensíveis.

Sob o ponto de vista quantitativo, de forma geral para os três fungicidas testados, os valores de $\mathrm{EC}_{50}$ para o método de microplacas foram significativamente menores em comparação com o método de placas de Petri, dentro do grupo fenotípico resistente (Figura 3).
Placa A

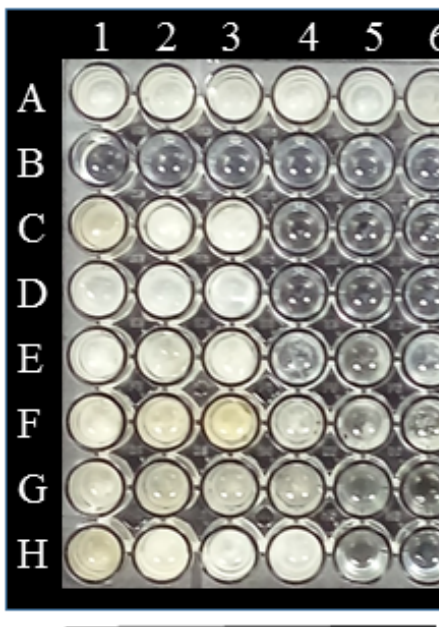

Tebuconazol $\begin{array}{llllllll}6 & 7 & 8 & 9 & 10 & 11 & 12\end{array}$
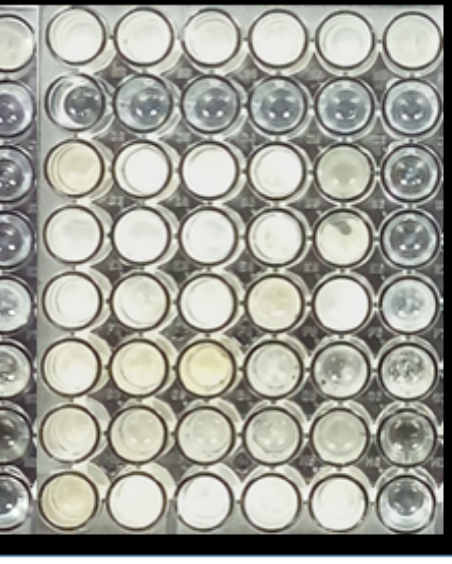

Epoxiconazol

\section{Placa B}

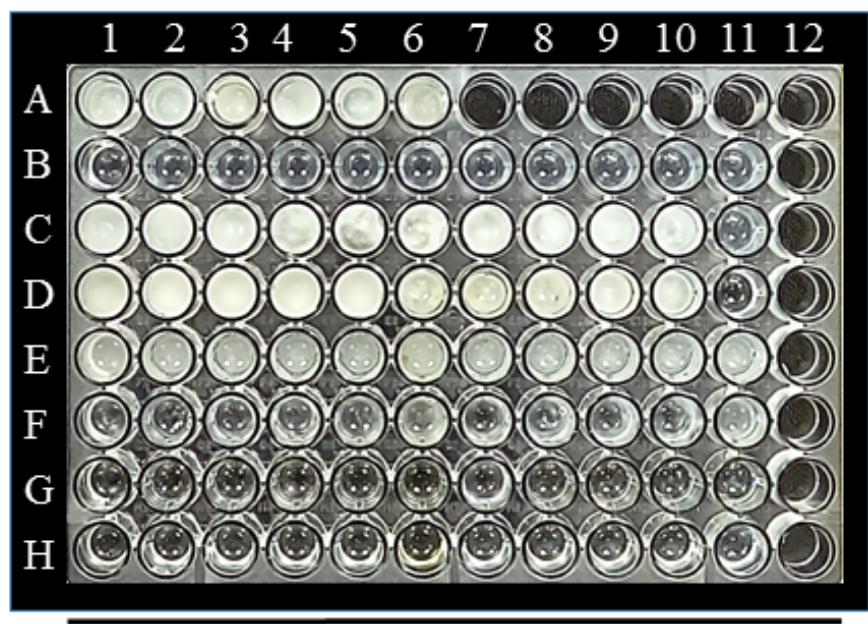

Azoxystrobina

Figura 1. Representação visual do crescimento de isolados de Pyricularia graminis-tritici in vitro em microplacas contendo caldo BD com diferentes concentrações dos fungicidas IDM triazóis, tebuconazol e epoxiconazol (placa A) e IQe azoxistrobina (placa B).

Placa A: Linha A, controle positivo contendo caldo BD sem o fungicida tebuconazol, com diferentes isolados de Pygt nas posição A1 a A6, e caldo BD sem o fungicida tebuconazol, com os mesmos isolados de Pygt nas posições de A7 a A12; linha B, controle negativo para isolados contento caldo BD com doses diferentes dos fungicidas tebuconazol (posições B1 á B6) ou epoxiconazol (posições B7 à B12), descritas Tabela 2); linhas C a H, contém diferentes isolados de Pygt e os números de $\mathrm{C} 1$ a $\mathrm{C} 6, \ldots, \mathrm{H} 1$ a $\mathrm{H} 6$ representam as doses crescentes de tebuconazol, e de $\mathrm{C} 7$ a $\mathrm{C} 12, \ldots, \mathrm{H} 7$ a $\mathrm{H} 12$, doses crescentes do fungicida epoxiconazol.

Placa B: Linha A, controle positivo contendo caldo BD sem o fungicida azoxistrobina, com diferentes isolados de Pygt nas posições A1 a, A6, e poços vazios nas posições A7 a A12; linha B, controle negativo para isolados com doses do fungicida azoxistrobina (posições B1 a B11); nas linhas C, D e E, isolados resistentes, linhas $\mathrm{F}, \mathrm{G}$ e $\mathrm{H}$, isolados sensíveis à azoxistrobina; e os números de 1 a 11 representam as doses crescentes de azoxistrobina. 

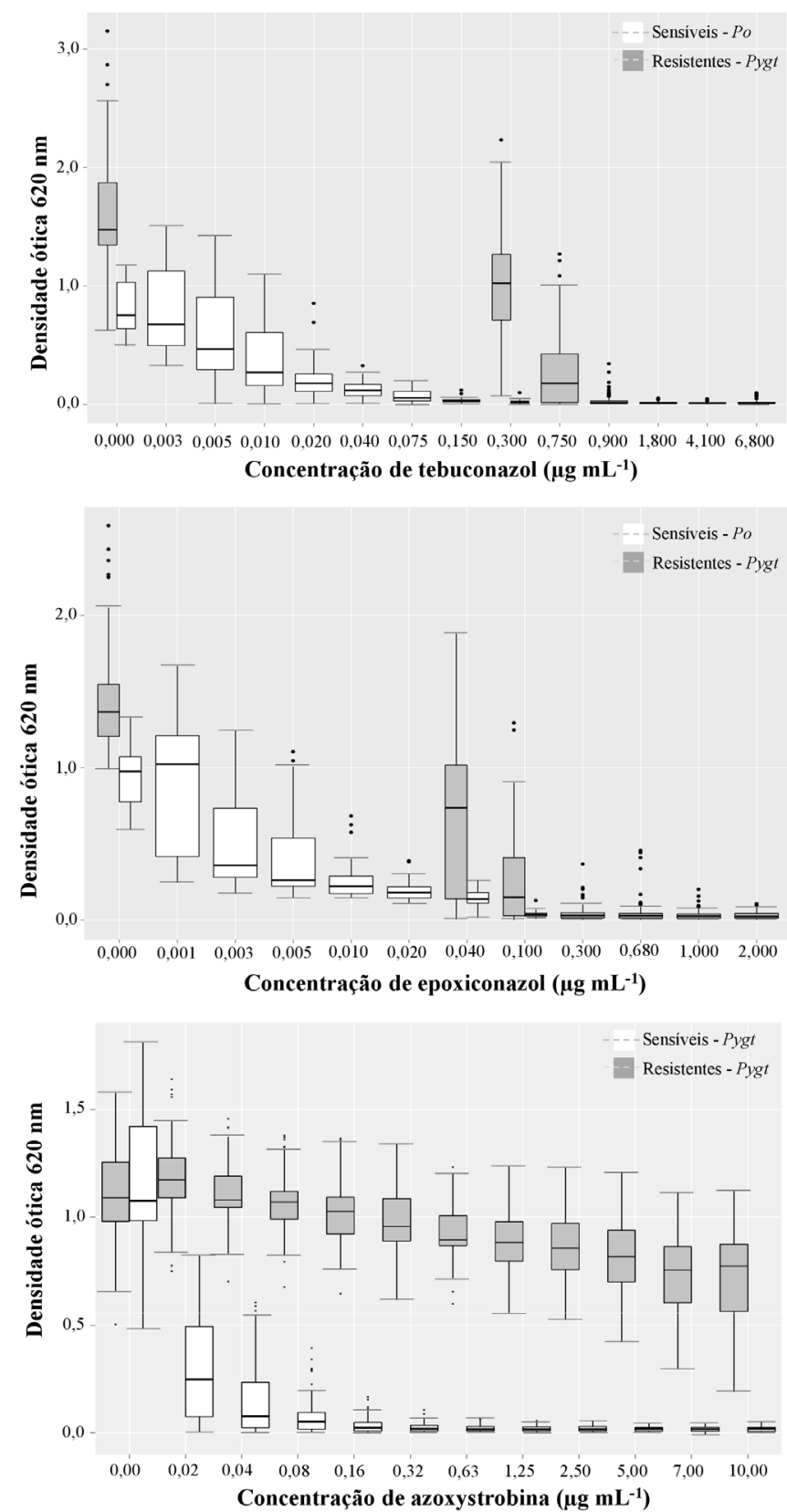

Figura 2. Curva dose-resposta do crescimento de Pyricularia graministritici (Pygt) e P. oryzae (Po) expresso em unidade de densidade ótica em função de doses dos fungicidas tebuconazol e epoxiconazol (IDM) e azoxistrobina (IQe) ${ }^{\text {a,b. }}$.

a Para fungicidas IDM triazóis, média de $N=13$ isolados resistentes de Pygt e $N=4$ isolados sensíveis de $P o$. ${ }^{b}$ Para fungicidas IQe estrobirulinas, média de $N=5$ isolados resistentes e $N=8$ isolados sensíveis de $P y g t$.

Em média, para o método de microplaca, a $\mathrm{EC}_{50}$ de isolados resistentes foi de $0,14 \pm 0,06 \mu \mathrm{g} \mathrm{mL}^{-1}$ de epoxiconazol, $0,61 \pm 0,19 \mu \mathrm{g}$ $\mathrm{mL}^{-1}$ de tebuconazol e $7.06 \pm 8.08 \mu \mathrm{g} \mathrm{mL} L^{-1}$ de azoxistrobina. Já para o método de placas de Petri, observou-se valores significativamente maiores de $\mathrm{EC}_{50}$ para isolados resistentes, como se segue: $1,22 \pm 0,14$ $\mu \mathrm{g} \mathrm{mL} \mathrm{m}^{-1}$ de epoxiconazol, $1,24 \pm 0,15 \mu \mathrm{g} \mathrm{mL}^{-1}$ de tebuconazol e 34,01 $\pm 29,93 \mu \mathrm{g} \mathrm{mL}^{-1}$ de azoxistrobina (Figura 3).

Por sua vez, não houve diferença significativa entre métodos dentro do grupo fenotípico sensível. Em média, para o método de microplaca, $\mathrm{aEC}_{50}$ de isolados sensíveis foi de $0,0074 \pm 0,0035 \mu \mathrm{g} \mathrm{mL}^{-1}$
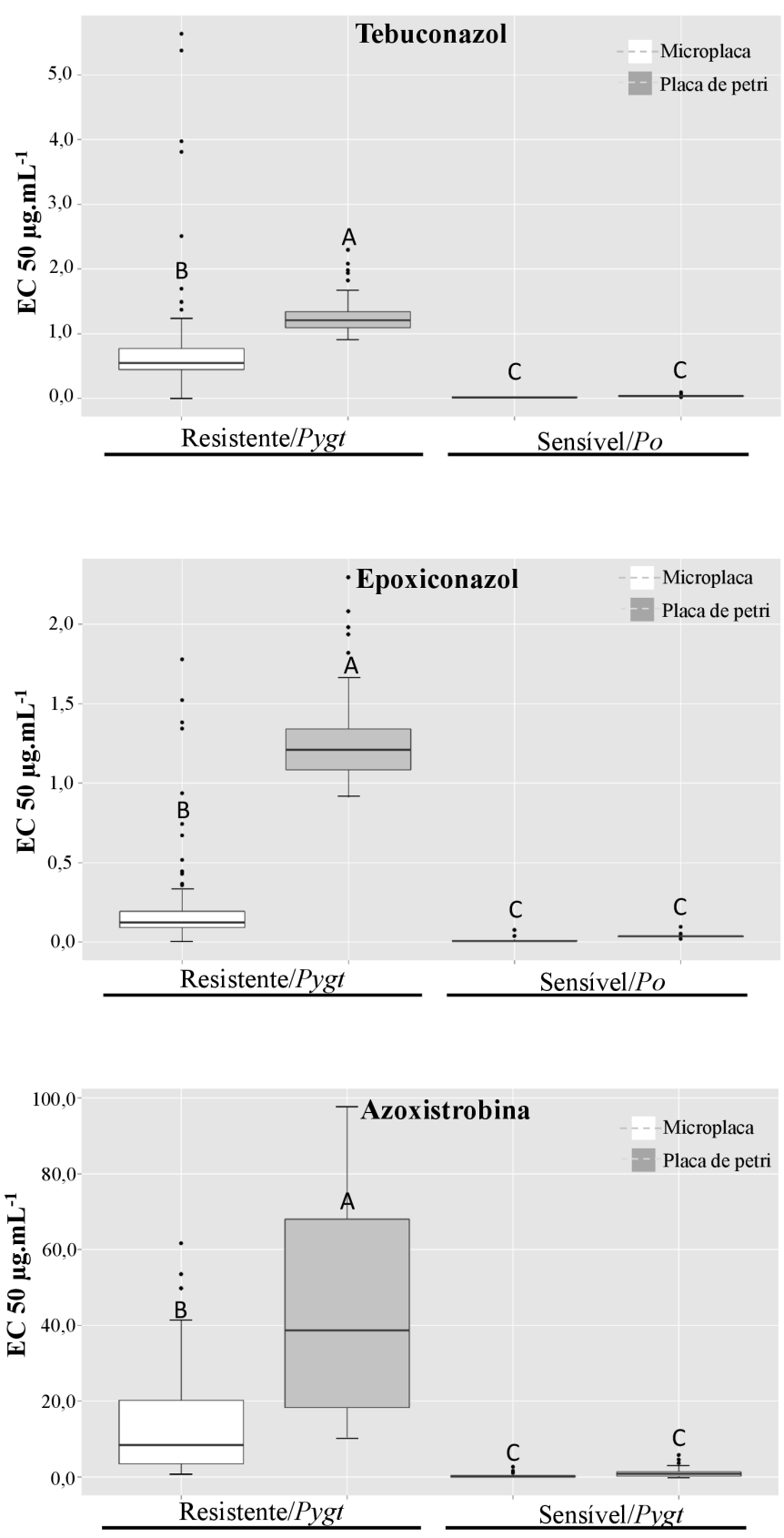

Figura 3. Boxplots representando a variação dos valores de $\mathrm{EC}_{50}$ de grupos de isolados de Pyricularia graminis-tritici e $P$. oryzae resistentes ou sensíveis aos fungicidas IDM triazóis (tebuconazol e epoxiconazol) ou IQe estrobirulinas (azoxistrobina) de acordo com método de microplacas (boxplot branco) e o método de placas de Petri (boxplot cinza) ${ }^{\mathrm{a}, \mathrm{b}, \mathrm{c}}$.

${ }^{a} A$ linha horizontal dentro do boxplot representa os valores das medianas correspondentes ao número de isolados de cada categoria e 10 repetições por grupo de isolados. ${ }^{\mathrm{b}}$ Medianas para grupos de isolados obtidas com $N=$ 13 isolados de Pygt resistentes e $N=4$ isolados de Po sensíveis a triazóis. ${ }^{c}$ Medianas para grupos de isolados obtidas $\operatorname{com} N=5$ isolados de $P y g t$ resistentes e $N=8$ isolados sensíveis a azoxistrobina. ${ }^{\mathrm{d}}$ Os boxplots com as mesmas letras indicam que as médias de métodos, dentro de grupo fenotípico, não diferem significativamente de acordo com o teste de Scott-Knott para comparação de médias a $p<0,05$. 
de epoxiconazol, $0,014 \pm 0,0059 \mu \mathrm{g} \mathrm{mL}{ }^{-1}$ de tebuconazol, e 1,47 $\pm 2,22$ $\mu \mathrm{g} \mathrm{mL}{ }^{-1}$ de azoxistrobina. Em comparação, para o método de placas de Petri, para isolados sensíveis observou-se $\mathrm{EC}_{50}$ de $0,034 \pm 0,0062 \mu \mathrm{g}$ $\mathrm{mL}^{-1}$ de epoxiconazol, $0,034 \pm 0,0062 \mu \mathrm{g} \mathrm{mL}^{-1}$ de tebuconazol e 1,02 $\pm 5,29 \mu \mathrm{g} \mathrm{mL}^{-1} \mathrm{de}$ azoxistrobina (Figura 3).

Muito embora com valores de $\mathrm{EC}_{50}$ significativamente menores, o método da microplaca foi semelhantemente acurado e de precisão superior ou similar (expressa pelos desvio da médios), permitindo discriminar os fenótipos de resistência dos de sensibilidade dos isolados de Pygt e/ou Po aos fungicidas tebuconazol, epoxiconazol e azoxistrobina (efeito significativo de grupos fenotípicos, Tabela 3). Reproduziu-se, assim, as observações dos estudos anteriores utilizando fenotipagem pelo método de placas de Petri $(24 ; 25)$.

Ainda quantitativamente, pelo método de microplaca detectou-se diferenças significativas entre isolados de Pgyt e/ou Po dentro dos grupos fenotípicos resistentes e sensíveis aos fungicidas tebuconazol, epoxiconazol e azoxistrobina, assim como detectado anteriormente usando-se o método de placas de Petri (Tabela 3).

Em seguida foi comparado o tempo para execução das técnicas de microplacas e de placas de Petri considerando a caracterização fenotípica de 30 isolados do patógeno, conforme fluxograma apresentado na Figura 4. O método de microplacas demandou 30 dias para se completar a fenotipagem dos 30 isolados, enquanto o de placas de Petri demandou 23 dias. Entretanto, ambos os métodos possuíam

Tabela 3. Análise de variância (ANOVA) de valores de $\mathrm{EC}_{50}$ comparando-se o efeito dos métodos de microplacas e de placas de Petri, e de grupos de isolados de Pyricularia graminis-tritici e de P. oryzae resistentes ou sensíveis aos fungicidas tebuconazol, epoxiconazol e azoxistrobina e as respectivas interações.

\begin{tabular}{|c|c|c|c|c|c|}
\hline Fungicida & Fatores de variação & G.L. & Q.M. & $F$ & $p>\mathbf{F}$ \\
\hline & Métodos & & & & \\
\hline & Método da microplaca & & & & \\
\hline \multirow[t]{11}{*}{ Tebuconazol } & Grupos fenotípicos & 1 & 7,244 & 616,46 & $<0,001 * * *$ \\
\hline & Isolados (Grupo) & 15 & 0,145 & 12,35 & $<0,001 * * *$ \\
\hline & Bloco & 9 & 0,091 & 0,86 & 0,565 \\
\hline & Resíduo & 88 & 0,012 & & \\
\hline & Método de placas de Petri & & & & \\
\hline & Grupos fenotípicos & 1 & 26,297 & 1473,63 & $<0,001 * * *$ \\
\hline & Isolados (Grupo) & 12 & 0,053 & 2,98 & $<0,01 * *$ \\
\hline & Bloco & 7 & 0,104 & 5,83 & $<0,001 * * *$ \\
\hline & Resíduo & 69 & 0,018 & & \\
\hline & Métodos & & & & \\
\hline & Método da microplaca & & & & \\
\hline \multirow[t]{11}{*}{ Epoxiconazol } & Grupos fenotípicos & 1 & 0,4371 & 239,66 & $<0,001 * * *$ \\
\hline & Isolados (Grupo) & 15 & 0,0154 & 8,42 & $<0,001 * * *$ \\
\hline & Bloco & 9 & 0,0050 & 2,74 & $<0,01 * *$ \\
\hline & Resíduo & 92 & 0,0018 & & \\
\hline & Método de placas de Petri & & & & \\
\hline & Grupos fenotípicos & 1 & 18,560 & 3957,77 & $<0,001 * * *$ \\
\hline & Isolados (Grupo) & 12 & 0,027 & 5,67 & $<0,001 * * *$ \\
\hline & Bloco & 7 & 0,027 & 5,68 & $<0,001 * * *$ \\
\hline & Resíduo & 58 & 0,005 & & \\
\hline & Método & 1 & & & \\
\hline & Método da microplaca & & & & \\
\hline \multirow[t]{9}{*}{ Azoxistrobina } & Grupos fenotípicos & 1 & 2731,8 & 83,86 & $<0,001 * * *$ \\
\hline & Isolados (Grupo) & 11 & 41,6 & 0,46 & 0,255 \\
\hline & Bloco & 9 & 15,0 & 1,28 & 0,896 \\
\hline & Resíduo & 75 & 32,6 & & \\
\hline & Método de placas de Petri & & & & \\
\hline & Grupos fenotípicos & 1 & 41018,0 & 115,42 & $<0,001 * * *$ \\
\hline & Isolados (Grupo) & 11 & 325,0 & 0,91 & 0,532 \\
\hline & Bloco & 7 & 403,0 & 1,13 & 0,354 \\
\hline & Resíduo & 65 & 355,0 & & \\
\hline
\end{tabular}

Em função de não ter sido detectado interação significativa entre réplicas dos experimentos e demais fatores, as réplicas foram combinadas. *** Significativa pelo teste $F$ a $p \leq 0,001$.

**Significativa a $p \leq 0,01$. 
atividades diárias que não ultrapassavam oito horas de trabalho, por exemplo o preparo de meio de cultura, a reativação de culturas fúngicas, a repicagem de culturas reativadas. Ainda, a incubação de culturas para crescimento micelial ou para produção de esporos, que varia de 7 a 15 dias, não demanda horas efetivas de trabalho e, portanto, permite a sobreposição de outros processos paralelos de fenotipagem, otimizando recursos e mão de obra disponível. No método de placas de Petri foi necessário um total de $52 \mathrm{~h}$ de trabalho, $14 \mathrm{~h}$ a mais que o requisitado para o método de microplacas, que totaliza $38 \mathrm{~h}$. Especificamente, são necessárias mais horas para preparo de meio de cultura em placas de Petri, para o estabelecimento e para a avaliação do experimento (Figura 4).

Quanto aos componentes que geraram consumo de energia, o método de placas de Petri requereu maior tempo para autoclavagem de material, maior tempo de uso da câmara de fluxo laminar para estabelecimento dos experimentos, além de quantidade consideravelmente maior de estufas incubadora (quatro, ao invés de uma) que resultou em consumo de energia elétrica equivalente a três vezes o consumo pelo método de microplacas (Tabela 4).

Foram comparados ainda os custos de investimentos requeridos pelos dois métodos de detecção de resistência a fungicidas.
Considerando que o laboratório dispõe de equipamentos básicos, tais como uma autoclave, uma câmara de fluxo laminar e estufas incubadoras (no mínimo uma), o investimento inicial para o sistema de microplacas foi de U\$ 6.208,49 (leitor de microplaca e micropipetas) enquanto que para o sistema de placas de Petri foi de U\$ 1.382,39 (micropipetas). Entretanto, para implementar o método de placas de Petri o laboratório necessitaria de outras três incubadoras disponíveis. Não havendo disponibilidade, deve ser adicionado o custo de U\$ 4.575,47 para aquisição das incubadoras, totalizando U\$ 5.957,86.

Dado ao alto valor de capital fixo para implantação de qualquer um dos dois métodos, é necessário avaliar, de forma integral, as necessidades de cada laboratório ou grupo de pesquisa para inovar e implementar o uso destas técnicas de detecção de resistência a fungicidas. Com relação à composição do custo operacional efetivo (COE), para o método de microplacas o gasto com mão de obra representou $71,0 \%$ dos custos de insumos (Tabela 4 ), seguido da energia elétrica, que representou $15,1 \%$ dos custos. Já para o método da placa de Petri o gasto com mão de obra representou 46,5\% dos custos enquanto a energia elétrica representou $30,8 \%$. Destaca-se que o custo operacional total (COT) para o método de microplaca foi de U\$739,04 o qual é 33,0\% inferior ao COT do método de placas de Petri (Tabela

\begin{tabular}{|c|c|c|c|c|c|}
\hline \multirow{2}{*}{\multicolumn{2}{|c|}{ Fluxograma de atividades }} & \multicolumn{2}{|c|}{ Microplaca } & \multirow{2}{*}{\multicolumn{2}{|c|}{ Placa de petri }} \\
\hline & & & & & \\
\hline \multirow[t]{2}{*}{ Dia } & \multirow[t]{2}{*}{ Atividades } & $\begin{array}{l}\text { início das } \\
\text { atividades) }\end{array}$ & $\begin{array}{l}\text { despendidas por } \\
\text { atividade no }\end{array}$ & $\begin{array}{l}\text { início das } \\
\text { atividades) }\end{array}$ & $\begin{array}{l}\text { despendidas por } \\
\text { atividade no }\end{array}$ \\
\hline & & & metodo (h) & & método $(\mathrm{h})$ \\
\hline 1 & Preparo de meio para reativar culturas fúngicas & 1 & 4 & 1 & 4 \\
\hline 2 & Reativação de culturas fúngicas & 1 & 4 & 1 & 4 \\
\hline 3 & Incubação de culturas fúngicas reativadas & 7 & 1 & 7 & 1 \\
\hline 8 & Preparo de meio de cultura para produção de inóculo & $1^{*}$ & 8 & 1 & 8 \\
\hline 9 & Repicagem de culturas reativadas & 1 & 8 & 1 & 8 \\
\hline 10 & Incubação de culturas para produção de esporos para microplacas / & 15 & 1 & & - \\
\hline & Incubação de culturas para crescimento micelial de inóculo para placas de petri & - & & 7 & 1 \\
\hline 15 & Preparo de meio e distribuição para experimentos em placas de Petri & - & - & 1 & 8 \\
\hline 16 & Estabelecimento de experimento em placas de petri & - & - & 1 & 8 \\
\hline 17 & Incubação de culturas em placas de petri & - & - & 7 & 2 \\
\hline 23 & Avalição de experimento de placas de petri & - & - & 1 & 8 \\
\hline 25 & Preparo e distribuição de meio de cultura em microplacas / & 0,5 & 4 & - & - \\
\hline & Estabelecimento de experimento em microplacas & 0,5 & 4 & - & - \\
\hline 26 & Incubação de culturas fúngicas em microplacas & 5 & 1 & - & - \\
\hline 30 & Avaliação de experimento em microplacas & 1 & 2 & & - \\
\hline & Total & 30 dias & $38 \mathrm{~h}$ & 23 dias & $52 \mathrm{~h}$ \\
\hline
\end{tabular}

Figura 4. Cronograma comparativo de atividades para estabelecimento de experimentos de detecção de resistência à fungicidas in vitro pelos métodos de microplaca e placa de Petri, $2017^{\text {a }}$

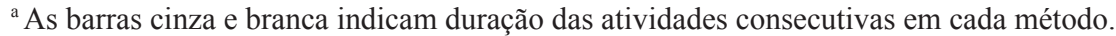


Tabela 4. Valores detalhados de custo discriminando gastos de energia e tempo dispendido em cada atividade para os métodos de microplaca e de placa de Petri, 2017

\begin{tabular}{|c|c|c|c|c|c|c|}
\hline \multirow[b]{2}{*}{ Ítem e detalhamento das atividades geradoras de consumo de energia } & \multicolumn{3}{|c|}{ Microplacas } & \multicolumn{3}{|c|}{ Placas de Petri } \\
\hline & $\begin{array}{c}\text { Potência } \\
\mathbf{k W}^{\mathrm{a}}\end{array}$ & Horas & Valor (U\$) & Potência kWa & Horas & Valor (U\$) \\
\hline 1. Energia consumida pelo uso da autoclave $\mathrm{b}^{\mathrm{b}}$ & 2,7 & 1 & 1.02 & 2,7 & 4 & 4.10 \\
\hline 2. Energia consumida pelo uso da câmara de fluxo laminar ${ }^{c}$ & 0,4 & 4 & 0.6 & 0,4 & 10 & 1.52 \\
\hline 3. Energia consumida pelo uso de incubadoras tipo BODs ${ }^{\mathrm{d}}$ & 0,4 & 648 & 98.62 & 1,6 & 504 & 306.83 \\
\hline 4. Tempo de avaliação de experimento em leitor de microplaca & 0,06 & 0,25 & 0.003 & - & 8 & - \\
\hline Total & - & & 100.24 & - & & 312.45 \\
\hline
\end{tabular}

Tabela 5. Estimativa de custos considerando o número de 30 isolados para os métodos de microplaca e placa de Petri para detecção de resistência a fungicidas em populações de fungos fitopatogênicos, 2017.

\begin{tabular}{|c|c|c|c|c|c|c|c|c|}
\hline \multirow[b]{2}{*}{ Descrição } & \multicolumn{3}{|c|}{ Método de microplacas } & \multicolumn{5}{|c|}{ Método de placas de Petri } \\
\hline & $\begin{array}{c}\text { Quantidade } \\
\text { (Unidades ou } \\
\text { gramas) }\end{array}$ & $\begin{array}{c}\text { Valor } \\
\text { Unit. (US) }\end{array}$ & $\begin{array}{c}\text { Valor } \\
\text { Total (US) }\end{array}$ & $\%$ & $\begin{array}{c}\text { Quantidade } \\
\text { (Unidades ou } \\
\text { gramas) }\end{array}$ & $\begin{array}{l}\text { Valor } \\
\text { Unit. } \\
\text { (U\$) }\end{array}$ & $\begin{array}{c}\text { Valor } \\
\text { Total (U\$) }\end{array}$ & $\%$ \\
\hline Mão de Obra & 1 & 471.69 & 471.69 & 70,99 & 1 & 471.69 & 471.69 & 46,54 \\
\hline Energia elétrica & - & - & 100.24 & 15,09 & - & - & 312.45 & 30,83 \\
\hline Microplacas de cultura ( 96 poços) & 5 & 1.41 & 7.07 & 1,06 & 0 & 0,00 & 0,00 & - \\
\hline Placas de Petri descartáveis 90x15mm & 180 & 0.15 & 28.30 & 4,26 & 810 & 0.15 & 127.35 & 12,56 \\
\hline Ponteira de $20-200 \mu \mathrm{L}$, com filtro & 60 & 0.07 & 4.52 & 0,68 & 12 & 0.07 & 0.90 & 0,09 \\
\hline Ponteira de $0.5-10 \mu \mathrm{L}$, com filtro & 60 & 0.06 & 3.96 & 0,60 & 12 & 0.06 & 0.79 & 0,08 \\
\hline Tubos falcons $(15 \mathrm{ml})$ & 60 & 0.17 & 10.56 & 1,59 & 0 & 0,00 & 0,00 & - \\
\hline Botijão de gás & 1 & 16.98 & 16.98 & 2,56 & 1 & 16.98 & 16.98 & 1,68 \\
\hline Caldo Batata dextrose (500g) & $68,31 \mathrm{~g}$ & 78.30 & 10.69 & 1,60 & $232,87 \mathrm{~g}$ & 78.30 & 36.46 & 3,60 \\
\hline Agar $(500 \mathrm{~g})$ & $37,5 \mathrm{~g}$ & 139.10 & 10.43 & 1,57 & $168,75 \mathrm{~g}$ & 139.10 & 46.94 & 4,63 \\
\hline Custo Operacional Efetivo (COE) & & & 664.44 & & & & $1,013.56$ & \\
\hline Outras Despesas (5\% COE) & & & 41.38 & & & & 39.71 & \\
\hline Depreciação Linear & & & 33.22 & & & & 50.68 & \\
\hline Custo Operacional Total (COT) & & & 739.04 & 100 & & & $1,103.95$ & 100 \\
\hline
\end{tabular}

5).

Outras contribuições científicas na área de detecção de resistência de fitopatógenos a fungicidas em outros patossistemas advogam favoravelmente pela utilização do método de microplacas. Segundo Vega et al. (30), o método de microplacas para análise da sensibilidade de Alternaria alternada de tangerinas à fungicidas QoI teve vantagens sobre o método convencional de placas de Petri, pois permitiu a avaliação de múltiplos isolados e concentrações seriadas de fungicidas ao mesmo tempo. Já Cox et al. (8) qualificaram e quantificaram a sensibilidade de Monilinia fructicola a fungicidas triazóis usando o método de microplacas. Segundo os autores, o método pode ser considerado acurado, rápido e de fácil reprodução quando comparado aos métodos convencionais.

Conclui-se, com esse estudo, que o método da microplaca permitiu discriminar com acurácia e maior rapidez os fenótipos de resistência e sensibilidade a triazóis e estrobirulinas em populações de isolados do patógeno da brusone do trigo.
O método de microplacas foi, também, mais eficiente no uso de recursos, com custo operacional inferior ao do método de placas de Petri. Em conjunto, os fatores acurácia, rapidez e eficiência no uso de recursos indicam que o método de microplaca pode ser incorporado no desenvolvimento de um sistema de monitoramento da sensibilidade a fungicidas em populações do fungo da brusone do trigo no agroecossistema brasileiro.

\section{AGRADECIMENTOS}

Este estudo foi financiado por auxílios à pesquisa da FAPESP (Fundação de Âmparo à Pesquisa do Estado de São Paulo) a P. C. Ceresini (2013/10655-4 e 2015/10453-8) e da Embrapa/Monsanto Macrograma II (SEG 02.11.04.006.00.00) a J. L. N. Maciel. P.C. Ceresini é Pesquisador Pq-2 do CNPq - Conselho Nacional de Desenvolvimento Científico e Tecnológico (Pq-2 307361/2012-8 e 
307295/2015-0). V. L. Castroagudín foi bolsista de pós-doutorado pelo convênio FAPESP/CAPES (2014/25904-2). G. Carvalho foi bolsista de pós-doutorado do Programa PNPD - CAPES (Coordenação de Aperfeiçoamento de Pessoal de Nível Superior) pelo Programa de Pósgraduação em Agronomia (PPGA) da UNESP Campus de Ilha Solteira. P. S. Casado foi bolsista de mestrado da CAPES pelo PPGA. S. N. C. Vicentini é bolsista de mestrado da FAPESP (2017/03403-0) no PPGA. Agradecemos à CAPES por conceder auxílio para estabelecimento do "Centro de Diversidade Genética no Agroecossistema" (Proequipamentos 775202/2012).

\section{REFERÊNCIAS}

1. Arikan, S. Current status of antifungal susceptibility testing methods. Medical Mycology, Wilmington, v.45, p.495-587, 2007.

2. Bampi, D.; Casa, R.T.; Wordell Filho, J.A.; Blum, M.M.C.; Camargo, M.P. Sensibilidade de Stenocarpella macrospora a fungicidas. Bioscience Journal, Uberlândia, v.29, n.4, p.787-795, 2013.

3. Botelho, T.S.; Lourenço, F.R.; Pinto, T.J.A. Vancomycin microbial assay using kinetic-reading microplate system. Current Pharmaceutical Analysis, Saif Zone, v.9, n.2, p.172-176, 2013.

4. Broekaert, W.F.; Terras, F.R.G.; Cammue, B.P.A.; Vanderleyden, J. An automated quantitative assay for fungal growth inhibition. FEMS Microbiology Letters, Oxford, v.69, p.55-60, 1990.

5. Castroagudín, V.L.; Ceresini, P.C.; Oliveira, S.C.; Reges, J.T.A.; Maciel, J.L.N.; Bonato, A.L.V.; Dorigan, A.F.; Mcdonald, B.A. Resistance to QoI fungicides is widespread in Brazilian populations of the wheat blast pathogen Magnaporthe oryzae. Phytopathology, Saint Paul, v.105, n.3, p.284-294, 2015.

6. Cools, H.J.; Bayon, C.; Atkins, S.; Lucas, J.A.; Fraaije, B.A. Overexpression of the sterol $14 \alpha$-demethylase gene $(M g C Y P 51)$ in Mycosphaerella graminicola isolates confers a novel azole fungicide sensitivity phenotype. Pest Management Science, West Sussex, v.68, n.7, p.1034-1040, 2012.

7. Cools, H.J.; Parker, J.E.; Kelly, D.E.; Lucas, J.A.; Fraaije, B.A.; Kelly, S.L. Heterologous expression of mutated eburicol 14alpha-demethylase (CYP51) proteins of Mycosphaerella graminicola to assess effects on azole fungicide sensitivity and intrinsic protein function. Applied and Environmental Microbiology, Washington, v.76, n.9, p.2866-2872, 2010.

8. Cox, K.D.; Quello, K.; Deford, R.J.; Beckerman, J.L. A rapid method to quantify fungicide sensitivity in the brown rot pathogen Monilinia fructicola. Plant Disease, Saint Paul, v.93, p.328-331, 2009.

9. Deising, H.B.; Reimann, S.; Pascholati, S.F. Mechanisms and significance of fungicide resistance. Brazilian Journal of Microbiology, Rio de Janeiro, v.39, p.286-295, 2008.

10. Dorigan, A.F.; Carvalho, G.; Poloni, N.M.; Negrisoli, M.M.; Maciel, J.L.N.; Ceresini, P.C. Resistance to triazole fungicides in Pyricularia species associated with invasive plants from wheat fields in Brazil. Acta Scientiarum Agronomy, Maringá, v.40, n.2, 2018.

11. Estep, L.K.; Torriani, S.F.F.; Zala, M.; Anderson, N.P.; Flowers, M.D.; Mcdonald, B.A.; Mundt, C.C.; Brunner, P.C. Emergence and early evolution of fungicide resistance in North American populations of Zymoseptoria tritici. Plant Pathology, Oxford, v.64, n.4, p.961-971, 2015.

12. Forcelini, C.A. Fungicidas inibidores da síntese de esteróis. Revisão Anual de Patologia de Plantas, Passo Fundo, v.2, p.335-355, 1994.

13. Forcelini, C.A.; Goellner, C.I.; May-De Mio, L.L. Resistência de fungos a fungicidas. Revisão Anual de Patologia de Plantas, Passo Fundo, v.9, p.339-381, 2001.

14. Fraaije, B.A.; Bayon, C.; Atkins, S.; Cools, H.J.; Lucas, J.A.; Fraaije, M.W. Risk assessment studies on succinate dehydrogenase inhibitors, the new weapons in the battle to control Septoria leaf blotch in wheat. Molecular Plant Pathology, Oxford, v.13, n.3, p.263-275, 2012.

15. Fraaije, B.A.; Cools, H.J.; Kim, S.H.; Motteram, J.; Clark, W.S.; Lucas, J.A. A novel substitution I381V in the sterol 14alpha-demethylase (CYP51) of Mycosphaerella graminicola is differentially selected by azole fungicides. Molecular Plant Pathology, Oxford, v.8, n.3, p.245-54, 2007.

16. Leroux, P.; Albertini, C.; Gautier, A.; Gredt, M.; Walker, A.-S. Mutations in the CYP51 gene correlated with changes in sensitivity to sterol $14 \alpha-$ demethylation inhibitors in field isolates of Mycosphaerella graminicola. Pest Management Science, West Sussex, v.63, n.7, p.688-698, 2007.

17. Lourenço, F.R.; Pinto, T.J.A. Antibiotic microbial assay using kinetic-reading microplate system. Brazilian Journal of Pharmaceutical Sciences, São Paulo, v.47, n.3, p.573-584, 2011.

18. Lucas, J.A.; Hawkins, N.J.; Fraaije, B.A. The evolution of fungicide resistance. Advances in Applied Microbiology, San Diego, v.90, p.29-92, 2015.

19. Ludwing, A.; Boller, T. A method for the study of fungal growth inhibition by plant proteins. FEMS Microbiology Letters, Oxford, v.69, p.61-66, 1990.

20. Ma, Z.; Proffer, T.J.; Jacobs, J.L.; Sundin, G.W. Overexpression of the $14 \alpha$-demethylase target gene (CYP51) mediates fungicide resistance in Blumeriella jaapii. Applied and Environmental Microbiology, Washington, v.72, n.4, p.2581-2585, 2006.

21. Maciel, J.L.N.; Ceresini, P.C.; Castroagudin, V.L.; Zala, M.; Kema, G.H.J.; Mcdonald, B.A. Population structure and pathotype diversity of the wheat blast pathogen Magnaporthe oryzae 25 years after its emergence in Brazil. Phytopathology, Saint Paul, v.104, n.1, p.95-107, 2014.

22. Matsunaga, M.; Bemelmans, P.F.; Toledo, P.E.N.; Dulley, R.D.; Okawa, H.; Pedroso, I.A. Metodologia de custo de produção utilizada pelo IEA. Agricultura em São Paulo, São Paulo, v.23, n.1, p.123-139, 1976.

23. May-De Mio, L.L.; Luo, Y.; Michailides, T.J. Sensitivity of Monilinia fructicola from Brazil to tebuconazole, azoxystrobin, and thiophanate-methyl and implications for disease management. Plant Disease, Saint Paul, v.95, n. 7, p.821-827, 2011.

24. Oliveira, S.C.; Castroagudín, V.L.; Maciel, J.L.N.; Pereira, D.A.S.; Ceresini, P.C. Resistência cruzada aos fungicidas IQo azoxistrobina e piraclostrobina no patógeno da brusone do trigo Pyricularia oryzae no Brasil. Summa Phytopathologica, Botucatu, v.41, p.298-304, 2015.

25. Poloni, N.M.; Carvalho, G.; Dorigan, A.F.; Maciel, J.L.N.; McDonald, B.A. Ceresini, P.C. Widespread distribution of resistance to triazole fungicides in populations of the wheat blast pathogen in Brazil and evolution of the cyp $51 \mathrm{~A}$ gene. In: International workshop on wheat blast, 2., 2016, Florianópolis. Book of Abstracts. Passo Fundo: Universidade de Passo Fundo, 2016. p152-152.

26. R Development Core Team. R: a language and environment for statistical computing. Vienna: R Roundation for Statistical Computing, 2013.

27. Rekanovic, E.M.M.; Potocnik, I. In vitro sensitivity of Fusarium graminearum (Schwabe) to difenoconazole, prothioconazole and thiophanate-methyl. Pesticides Phytomedicine, Beograd, v.25, p.325-333, 2010.

28. Van Den Bosch, F.; Oliver, R.; Van Den Berg, F.; Paveley, N. Governing principles can guide fungicide-resistance management tactics. Annual Review of Phytopathology, Palo Alto, v.52, n.1, p.175-195, 2014.

29. Vargas, M.H. ED50plus v1.0. Mexico City: Instituto Nacional de Enfere medades Respiratorias, 2000.

30. Vega, B.; Liberti D.; Harmon, P.F.; Dewdney, M.M. A rapid resazurin-based microtiter assay to evaluate QoI sensitivity for Alternaria alternata isolates and their molecular characterization. Plant Disease, Saint Paul, v.96, p.1262-1270, 2012. 